\title{
Dapsone: A Novel Corrosion Inhibitor for Mild Steel in Acid Media
}

\author{
Ambrish Singh $^{\mathrm{a}}$, Ashish Kumar Singh ${ }^{\mathrm{b}}$ and M. A. Quraishi ${ }^{\mathrm{b}, *}$ \\ ${ }^{a}$ Department of Chemistry, Udai Pratap Autonomous College, Varanasi 221002, India \\ ${ }^{b}$ Department of Applied Chemistry, Institute of Technology Banaras Hindu University, Varanasi 221005, India
}

\begin{abstract}
Corrosion inhibition of mild steel in $1 \mathrm{M} \mathrm{HCl}$ and $0.5 \mathrm{M} \mathrm{H}_{2} \mathrm{SO}_{4}$ by dapsone were studied by polarization resistance, Tafel polarization, electrochemical impedance spectroscopy (EIS) and weight loss measurement. Results obtained revealed that inhibition occurs through adsorption of the drug on metal surface without modifying the mechanism of corrosion process. Potentiodynamic polarization suggested that it acts as a mixed type predominantly cathodic in $\mathrm{HCl}$ and predominantly anodic in $\mathrm{H}_{2} \mathrm{SO}_{4}$. Electrochemical impedance spectroscopy was used to investigate the mechanism of corrosion inhibition. Thermodynamic parameters such as $E_{\mathrm{a}}, \Delta H_{\mathrm{a}}^{\circ}, \Delta S_{\mathrm{a}}^{\circ}, \Delta H_{\text {ads }}^{\circ}$ were calculated to investigate mechanism of inhibition. The adsorption of dapsone followed Langmuir adsorption isotherm.
\end{abstract}

Keywords: Mild steel, Acid solution, weight loss, EIS, Drug.

\section{INTRODUCTION}

Inhibition of corrosion of mild steel is a matter of theoretical as well as practical importance [1]. Acids are widely used in industries such as pickling, cleaning, descaling etc. Because of their aggressiveness, inhibitors are used to reduce the rate of dissolution of metals. Compounds containing nitrogen, sulphur and oxygen have been reported as excellent inhibitors [2-7]. The efficiency of an organic compound as an inhibitor is mainly dependent on its ability to get adsorbed on metal surface which consists of a replacement of water molecule at a corroding interface. The adsorption of these compounds is influenced by the electronic structure of inhibiting molecules, steric factor, aromatic, and electron density at donor site, presence of functional group such as - $\mathrm{CHO}$, $\mathrm{N}=\mathrm{N}, \mathrm{R}-\mathrm{OH}$ etc., molecular area and molecular weight of the inhibitor molecule [8-11].

A large number of organic compounds are known to be applicable as corrosion inhibitors for mild steel [12, 13]. However, only a few non-toxic and eco-friendly compounds have been investigated as corrosion inhibitors. Tryptamine, Succinic acid, L-ascorbic acid, Sulfamethoxazole and Cefatrexyl, were found to be effective inhibitors for acid environments. Dithiobiurets exhibited the best performance towards the corrosion of mild steel in $\mathrm{HCl}$ solutions showed very less toxicity [14-19]. The inhibitive effect of four antibacterial drugs, namely Ampicillin, Cloxacillin, Flucloxacillin and Amoxicillin towards the corrosion of aluminum was investigated [20]. The inhibition action of these drugs was attributed to blocking the surface via formation of insoluble complexes on the metal surface.

Dapsone (diamino-diphenyl sulfone) is a pharmacological medication most commonly used in combination

*Address correspondence to this author at the Department of Applied Chemistry, Institute of Technology Banaras Hindu University, Varanasi 221005, India; Tel: +91-9307025126; Fax: +91- 542- 2368428;

E-mails: maquraishi@rediffmail.com,maquraishi.apc@itbhu.ac.in with rifampicin and clofazimine as multidrug therapy (MDT) for the treatment of Mycobacterium leprae infections (leprosy). It is also used to treat Pneumocystis carinii pneumonia (PCP) caused by Pneumocystis jiroveci (formerly $P$. carinii). Dapsone is used in combination with Pyrimethamine in the treatment of malaria. Dapsone-USP, 4, 4'-diaminodiphenylsulfone (DDS) is a primary treatment for Dermatitis herpetiformis. It is an antibacterial drug for susceptible cases of leprosy.

The objective of this study to investigate the corrosion behavior of mild steel in $1 \mathrm{M} \mathrm{HCl}$ and $0.5 \mathrm{M} \mathrm{H}_{2} \mathrm{SO}_{4}$ solution at $308 \mathrm{~K}$ in the presence of dapsone using weight loss, polarization resistance, Tafel polarization and electrochemical impedance techniques. The effects of temperature, acid concentration, immersion time were also studied. Several isotherms were tested for their relevance to describe the adsorption behavior of the compounds studied.

\section{EXPERIMENTAL}

The mild steel strips having composition (wt \%): C 0.04, Mn 0.035, Si 0.17, S 0.025, P 0.03 and balance Fe were used for weight loss as well as electrochemical studies. The aggressive solution of hydrochloric acid (AR grade) is used for all studies. Its chemical structure is shown as Fig. (1). All the concentrations of the inhibitor taken for weight loss and electrochemical study, was taken in ppm by weight. The weight loss studies were done on mild steel strips of $2.0 \mathrm{~cm}$ $\times 2.5 \mathrm{~cm} \times 0.025 \mathrm{~cm}$ sizes. Weight loss studies were carried out at $308 \mathrm{~K}$ temperature and $3 \mathrm{~h}$ time duration and $1 \mathrm{M} \mathrm{HCl}$ and $0.5 \mathrm{M} \mathrm{H}_{2} \mathrm{SO}_{4}$ solution. The surface coverage $(\theta)$ and inhibition efficiency ( $\mu_{\mathrm{wL}} \%$ ) was determined by using following equation [21]:

$$
\begin{aligned}
& \theta=\frac{w_{0}-w_{\mathrm{i}}}{w_{0}} \\
& \mu_{\mathrm{WL}} \%=\frac{w_{0}-w_{\mathrm{i}}}{w_{0}} \times 100
\end{aligned}
$$


<smiles>Nc1ccc(OSc2ccc(N)cc2)cc1</smiles>

Fig. (1). Structure of Dapsone.

Where, $w_{\mathrm{i}}$ and $w_{0}$ are the weight loss values in presence and absence of inhibitor, respectively.

The corrosion rate $\left(C_{\mathrm{R}}\right)$ of mild steel was calculated using the relation:

$C_{\mathrm{R}}(\mathrm{mm} / \mathrm{y})=\frac{87.6 \times w}{a t D}$

where, $w$ is corrosion weight loss of mild steel (mg), $a$ the area of the coupon $\left(\mathrm{cm}^{2}\right), t$ is the exposure time (h) and $D$ the density of mild steel $\left(\mathrm{g} \mathrm{cm}^{-3}\right)$.

The electrochemical studies were made using a three electrode cell assembly at room temperature [22, 23]. The working electrode was a mild steel of above composition of $1 \mathrm{~cm}^{2}$ area and the rest being covered by using commercially available lacquer. A rectangular Platinum foil of $1 \mathrm{~cm}^{2}$ was used as counter electrode and saturated calomel electrode (SCE) as reference electrode. The working electrode was abraded with different grades of emery papers (600/800/ $1000 / 1200)$, washed with water and degreased with acetone. The polarization and impedance studies were carried out using Gamry Potentiostat/Galvanostat (model 300) with EIS software, Gamry-Instruments Inc., USA. The linear polarization study were carried out from cathodic potential of $-0.02 \mathrm{~V}$ $v s$. OCP to an anodic potential of $+0.02 \mathrm{~V}$ vs. OCP at a sweep rate $0.125 \mathrm{mVs}^{-1}$ to study the polarization resistance $\left(R_{\mathrm{p}) \text {. From }}\right.$ the measured polarization resistance value, the inhibition efficiency has been calculated using the relationship:

$\mu_{P} \%=\frac{R_{\mathrm{p}}^{\prime}-R_{\mathrm{p}}^{0}}{R_{\mathrm{p}}^{\prime}} \times 100$

Where, $R_{\mathrm{p}}^{0}$ and $R_{\mathrm{p}}^{\prime}$ are the polarization resistance in absence and in presence of inhibitor, respectively.
The Tafel polarization was carried out from cathodic potential of $-0.25 \mathrm{~V} v s$. OCP to an anodic potential of $+0.25 \mathrm{~V}$ $v s$. OCP at a sweep rate $1.0 \mathrm{mVs}^{-1}$ to study the effect of inhibitor on mild steel corrosion. The linear Tafel segment of anodic and cathodic curves were extrapolated to corrosion potential to obtain the corrosion current densities $\left(I_{\text {corr }}\right)$. The corrosion inhibition efficiency $(E \%)$ was evaluated from the measured $I_{\text {corr }}$ values using the relationship:

$\mu_{\mathrm{P}} \%=\frac{I_{\text {corr }}^{\mathrm{o}}-I_{\text {corr }}^{\prime}}{I_{\text {corr }}^{\mathrm{o}}} \times 100$

where, $I_{\text {corr }}^{\mathrm{o}}$ and $I_{\text {corr }}^{\mathrm{i}}$ are the corrosion current densities in absence and in presence of various concentrations of the inhibitor, respectively. The impedance studies were carried out using ac signals of $10 \mathrm{mV}$ amplitude for the frequency spectrum from $100 \mathrm{kHz}$ to $0.01 \mathrm{~Hz}$. The charge transfer resistance values were obtained from the diameter of the semi circles of the Nyquist plots. The inhibition efficiency of the inhibitor was calculated from the charge transfer resistance values using the following equation:

$\mu_{\mathrm{Rct}} \%=\frac{R_{\mathrm{ct}}^{\prime}-R_{\mathrm{ct}}^{\mathrm{o}}}{R_{\mathrm{ct}}^{\prime}} \times 100$

where, $R_{\mathrm{ct}}^{\mathrm{o}}$ and $R_{\mathrm{ct}}^{\prime}$ are the charge transfer resistance in absence and in presence of inhibitor, respectively.

\section{RESULTS AND DISCUSSION}

\subsection{Weight Loss Study}

The value of percentage inhibition efficiency $(E \%)$ and corrosion rate $\left(C_{\mathrm{R}}\right)$ obtained from weight loss method at different concentrations of Dapsone in $1 \mathrm{M} \mathrm{HCl}$ and $0.5 \mathrm{M}$ $\mathrm{H}_{2} \mathrm{SO}_{4}$ at $308 \mathrm{~K}$ are summarized in Table (1). The variation of inhibition efficiency with increase in inhibitor concentrations is shown in Fig. (2a). It was observed that dapsone inhibits the corrosion of mild steel in $\mathrm{HCl}$ and $\mathrm{H}_{2} \mathrm{SO}_{4}$ solution, at all concentrations used in study i.e. 100-400 ppm. Maximum inhibition efficiency was shown at 400 ppm concentration of the inhibitor in $1 \mathrm{M} \mathrm{HCl}$ and $0.5 \mathrm{M} \mathrm{H}_{2} \mathrm{SO}_{4}$ at

Table 1. Corrosion Parameters for Mild Steel in Aqueous Solution of $1 \mathrm{M} \mathrm{HCl}$ and $0.5 \mathrm{M} \mathrm{H}_{2} \mathrm{SO}_{4}$ in Absence and Presence of Different Concentrations of Dapsone from Weight Loss Measurements at $308 \mathrm{~K}$ for $3 \mathrm{~h}$

\begin{tabular}{|c|c|c|c|}
\hline Inhibitor Concentration (ppm) & Weight Loss $\left(\mathbf{m g ~ c m}{ }^{-2}\right)$ & $\boldsymbol{\mu}_{\mathrm{WL}}(\boldsymbol{\%})$ & $\boldsymbol{C}_{\mathrm{R}}(\mathbf{m m} / \mathbf{y})$ \\
\hline \hline $1 \mathrm{M} \mathrm{HCl}$ & 20.9 & - & 37.91 \\
\hline 100 & 8.2 & 60.95 & 21.14 \\
\hline 200 & 5.7 & 78.85 & 8.16 \\
\hline 300 & 2.2 & 89.52 & 5.19 \\
\hline 400 & 1.4 & 93.33 & 111.30 \\
\hline $0.5 \mathrm{M} \mathrm{H}_{2} \mathrm{SO}_{4}$ & 30.0 & - & 47.00 \\
\hline 100 & 12.7 & 57.66 & 27.82 \\
\hline 200 & 7.5 & 75.00 & 12.61 \\
\hline 300 & 3.4 & 88.66 & 10.38 \\
\hline
\end{tabular}


$308 \mathrm{~K}$. It is evident from the Table (1) that the corrosion rate is decreased from 77.91 to $5.19 \mathrm{~mm} / \mathrm{y}$ in $1 \mathrm{M} \mathrm{HCl}$ and from 111.3 to $10.38 \mathrm{~mm} / \mathrm{y}$ in $0.5 \mathrm{M} \mathrm{H}_{2} \mathrm{SO}_{4}$ respectively, on the addition of $400 \mathrm{ppm}$ of dapsone.

The effect of immersion time on the inhibition efficiency is shown in Fig. (2b). It is found that the inhibition efficiency decreases with increasing immersion time from 2 to 8 $\mathrm{h}$. This suggests that desorption of the inhibitor molecule from metal surface with increasing immersion time.

The variation of inhibition efficiency with increase in acid concentration from 0.5 to $2.0 \mathrm{M}$ is shown in Fig. (2c). It is clear that change in acid concentration from $0.5 \mathrm{M}$ to 2.0 $\mathrm{M}$, inhibition efficiency varied from 97.66 to $73.77 \%$, from 96.5 to $71.65 \%$ in $\mathrm{HCl}$ and $\mathrm{H}_{2} \mathrm{SO}_{4}$, respectively. This change in the inhibition suggests that the compound is not much effective corrosion inhibitor in acid solution at higher concentration of the acid solution.

The influence of solution temperature on inhibition efficiency is shown in Fig. (2d). It is observed that inhibition efficiency decreases with increase in temperature $308 \mathrm{~K}$ to $338 \mathrm{~K}$. The decrease in inhibition efficiency with temperature may be attributed to desorption of the inhibitor molecule from metal surface at higher temperature [24].

\subsection{Electrochemical Impedance Spectroscopy}

Electrochemical impedance measurements were carried over the frequency range from $10 \mathrm{kHz}$ to $0.01 \mathrm{~Hz}$ at open circuit potential. The impedance spectra for Nyquist plots were analyzed by fitting to the equivalent circuit model (Fig. 3) which was used elsewhere to describe iron / acid interface $[25,26]$. In this equivalent circuit, $R_{\mathrm{s}}$ is the solution resis-

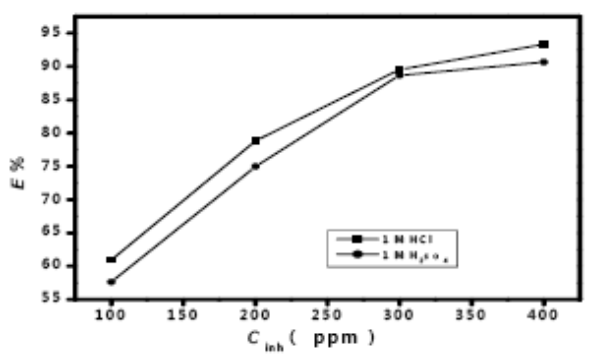

(a)

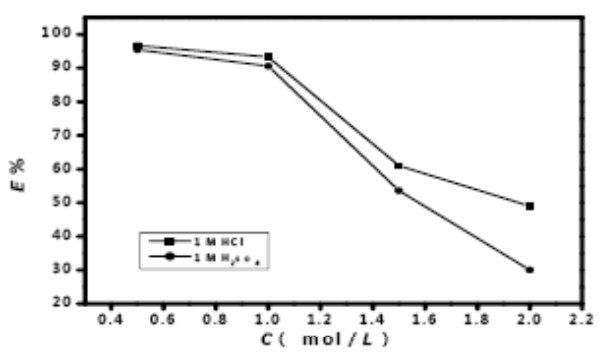

2

(c) tance, $R_{\mathrm{ct}}$ is the charge transfer resistance and CPE is a constant phase element. The capacitance values were calculated using the equation $[27,28]$. The impedance function of the $\mathrm{CPE}$ is as follows:

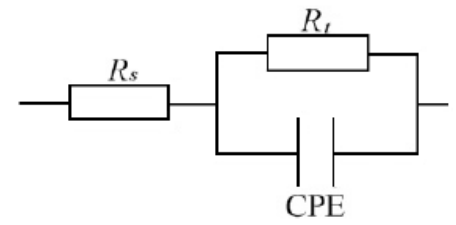

Fig. (3). Electrochemical equivalent circuit used to fit the impedance spectra.

$C_{\mathrm{dl}}=\left(Y_{\mathrm{o}} R_{\mathrm{ct}}{ }^{n-1}\right)^{1 / n}$

where $Y_{0}$ is the magnitude of CPE, $R_{\mathrm{ct}}$ is the charge transfer resistance and $n$ is the $\mathrm{CPE}$ exponent. Depending on $n, \mathrm{CPE}$ can represent resistance $(\mathrm{Y}-1=\mathrm{R}, \mathrm{n}=0)$, capacitance $(\mathrm{Y}-1=$ $\mathrm{C}, \mathrm{n}=1)$, inductance $(\mathrm{Y}-1=\mathrm{L}, \mathrm{n}=-1)$ and Warburg impedance for $n=0.5$ [29]. So, by use of the CPE concept we got excellent fit for the experimental data. The idealized capacitance $\left(C_{\mathrm{id}}\right)$ values were calculated from CPE parameter values $Y_{0}$ and $n$ using the relation [30].

$C_{\mathrm{id}}=\frac{Y / \omega^{n-1}}{\sin \left(n \frac{\pi}{2}\right)}$

The impedance parameters such as solution resistance $\left(R_{s}\right)$, charge transfer resistance $\left(R_{\mathrm{t}}\right), Y_{0}, n$, derived double layer capacitance $\left(C_{\mathrm{dl}}\right)$ and inhibition efficiency $(E \%)$ are listed in Table (2). The values of $E \%$ are calculated using the following equation:

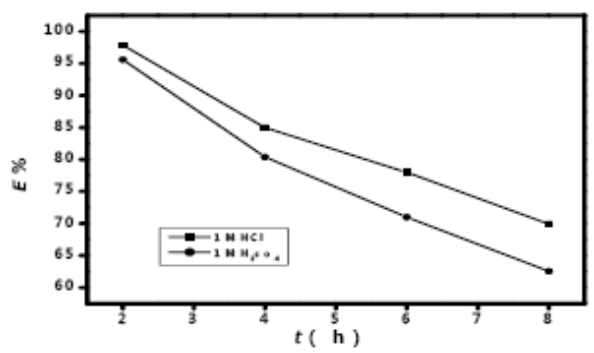

(b)

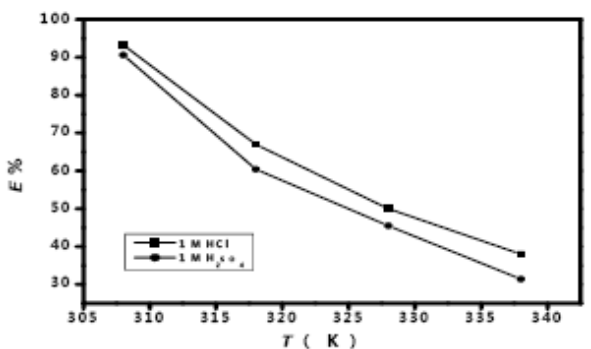

(d)

Fig. (2). Variation of inhibition efficiency of Dapsone in $1 \mathrm{M} \mathrm{HCl}$ and $0.5 \mathrm{M} \mathrm{H}_{2} \mathrm{SO}_{4}$ with (a) inhibitor concentration, (b) immersion time, (c) acid concentration and (d) temperature of the solution. 
Table 2. Impedance Parameters and Inhibition Efficiency Values for Mild Steel after 30 min Immersion Period in $1 \mathrm{M}$ HCl and $0.5 \mathrm{M} \mathrm{H}_{2} \mathrm{SO}_{4}$ in Absence and Presence of Different Concentrations of Dapsone

\begin{tabular}{|c|c|c|c|c|c|c|c|}
\hline Acid Solution & $\begin{array}{l}\text { Concentration of } \\
\text { Inhibitor (ppm) }\end{array}$ & $\begin{array}{c}R_{\mathrm{s}} \\
\left(\Omega \mathrm{cm}^{2}\right)\end{array}$ & $\begin{array}{c}R_{\mathrm{ct}} \\
\left(\Omega \mathrm{cm}^{2}\right)\end{array}$ & $\begin{array}{c}Y_{0} \\
\left(\mu \mathrm{F} \mathrm{cm}^{-2}\right)\end{array}$ & $n$ & $\begin{array}{c}C_{\mathrm{dl}} \\
\left(\mu \mathrm{F} \mathrm{cm}^{-2}\right)\end{array}$ & $\mu_{R_{\mathrm{ct}} \%}$ \\
\hline \multirow[t]{4}{*}{$1 \mathrm{M} \mathrm{HCl}$} & 0.0 & 1.20 & 8.461 & 250.0 & 0.827 & 68.97 & - \\
\hline & 200.0 & 1.91 & 41.63 & 153.5 & 0.857 & 66.05 & 79.62 \\
\hline & 300.0 & 1.04 & 95.73 & 125.1 & 0.868 & 63.86 & 91.62 \\
\hline & 400.0 & 0.81 & 125.80 & 102.8 & 0.877 & 55.86 & 93.27 \\
\hline \multirow[t]{4}{*}{$0.5 \mathrm{M} \mathrm{H}_{2} \mathrm{SO}_{4}$} & 0.0 & 1.51 & 4.50 & 180.0 & 0.883 & 71.35 & \\
\hline & 200.0 & 0.88 & 13.12 & 131.8 & 0.889 & 59.60 & 65.7 \\
\hline & 300.0 & 1.37 & 16.55 & 114.4 & 0.898 & 56.01 & 72.80 \\
\hline & 400.0 & 0.63 & 31.83 & 100.0 & 0.901 & 53.16 & 85.86 \\
\hline
\end{tabular}

$E(\%)=\frac{R_{\mathrm{t}, \mathrm{i}}-R_{\mathrm{t}, 0}}{R_{\mathrm{t}, \mathrm{i}}} \times 100$

where $R_{\mathrm{t}, \mathrm{i}}$ and $R_{\mathrm{t}, 0}$ are charge transfer resistances in presence and absence of inhibitor, respectively. It is clear from Table (2) that by increasing the inhibitor concentration, the $C_{\mathrm{dl}}$ values tend to decrease and the inhibition efficiency increases. The decrease in $C_{\mathrm{dl}}$ values can be attributed to a decrease in local dielectric constant and / or an increase in the thickness of the electrical double layer, suggesting that dapsone act by adsorption at the mild steel/solution interface [31]. On the other hand, the values of $\mathrm{C}_{\mathrm{dl}}$ decreased with an increase in the dapsone concentration. This situation was the result of an increase in the surface coverage by this inhibitor, which led to an increase in the inhibition efficiency. The thickness of the protective layer, $\delta_{\text {org }}$, was related to $\mathrm{C}_{\mathrm{dl}}$ by the following equation [32].

$$
\text { Sorg }=\frac{\varepsilon_{0} \varepsilon_{\mathbf{r}}}{\varepsilon_{\mathrm{dl}}}
$$

where,$\varepsilon_{0}$ is the dielectric constant and $\varepsilon_{\mathrm{r}}$ is the relative dielectric constant. This decrease in the $\mathrm{C}_{\mathrm{dl}}$, which can result from a decrease in local dielectric constant and/or an increase in the thickness of the electrical double layer, suggested that dapsone function by adsorption at the metal/ solution interface. Thus, the change in $\mathrm{C}_{\mathrm{dl}}$ values was caused by the gradual replacement of water molecules by the adsorption of the organic molecules on the metal surface, decreasing the extent of metal dissolution [33].

It is apparent from Nyquist plots that the impedance response of mild steel in inhibited $\mathrm{HCl}$ and $\mathrm{H}_{2} \mathrm{SO}_{4}$ solutions has significantly changed after the addition of dapsone in acid solutions and that the impedance of inhibited substrate increases with increasing conc. of inhibitor in both acids as in Fig. (4a-b). From the Table (2), it is clear that the greatest effect was observed at $400 \mathrm{ppm}$ of dapsone which gives $R_{\mathrm{ct}}$ values of 125.8 and $31.83 \Omega \mathrm{cm}^{2}$ in $1 \mathrm{M} \mathrm{HCl}$ and $0.5 \mathrm{M}$ $\mathrm{H}_{2} \mathrm{SO}_{4}$ respectively. Inhibition efficiency is found to increase with inhibitor concentration in both the acids, but it is found to be more effective in $\mathrm{HCl}$ than $\mathrm{H}_{2} \mathrm{SO}_{4}$ solution. The data obtained from EIS are in good agreement with those obtained from weight loss and potentiodynamic polarization methods.

\subsection{Tafel Polarization}

Fig. (5a-b) showed the Tafel polarization curve for mild steel in $1 \mathrm{M} \mathrm{HCl}$ and $0.5 \mathrm{M} \mathrm{H}_{2} \mathrm{SO}_{4}$ with addition of various concentrations of dapsone. The important corrosion parameters derived from these curves are presented in Table (3). From the Table 3 , it is clear that the corrosion current $\left(I_{\text {corr }}\right)$ value decreased from $1530 \mu \mathrm{Acm}^{-2}$ to $98 \mu \mathrm{Acm}^{-2}$ and from $4799 \mu \mathrm{Acm}^{-2}$ to $415 \mu \mathrm{Acm}^{-2}$ the presence of $400 \mathrm{ppm}$ concentration of dapsone in $1 \mathrm{M} \mathrm{HCl}$ and $0.5 \mathrm{M} \mathrm{H}_{2} \mathrm{SO}_{4}$ respectively. In $\mathrm{HCl}$ solution, both $b_{\mathrm{a}}$ and $b_{\mathrm{c}}$ values changed significantly and $E_{\text {corr }}$ shifted to cathodic region hence, dapsone acted as mixed type but predominantly cathodic where as in $\mathrm{H}_{2} \mathrm{SO}_{4}$ solution $b_{\mathrm{c}}$ values changed less prominently in comparison to that of $b_{\mathrm{a}}$ and $E_{\text {corr }}$ shifted to anodic region. Thus, dapsone acted as anodic inhibitor in $\mathrm{H}_{2} \mathrm{SO}_{4}$.

\subsection{Polarization Resistance}

The polarization resistance $\left(R_{\mathrm{p}}\right)$ values of mild steel in 1 $\mathrm{M} \mathrm{HCl}$ and $0.5 \mathrm{M} \mathrm{H}_{2} \mathrm{SO}_{4}$ increases from $9.70 \Omega \mathrm{cm}^{2}$ of the blank to $262.9 \Omega \mathrm{cm}^{2}$ and from $3.25 \Omega \mathrm{cm}^{2}$ to $39.70 \Omega \mathrm{cm}^{2}$ respectively in the presence of $400 \mathrm{ppm}$ concentration of dapsone (Table 3). The increase in the $R_{\mathrm{p}}$ value suggests that the inhibition efficiency increases with the increase in the inhibitor concentration.

\subsection{Adsorption Isotherm and Thermodynamic Parameter}

The plot between ln $\mathrm{K}_{\mathrm{ads}}$ vs. 1/T as in Fig. (6) gives the values for calculating, heat of adsorption $(\Delta H)$ with a slope $(-\Delta H / 2.303 R)$. The values for heat of adsorption are included in Table (4). Since the values of heat of adsorption for the inhibitor is less that $-40 \mathrm{~kJ} \mathrm{~mol}^{-1}$, hence physical adsorption occurs [34].

It has been reported by number of authors [35-37] that in acid solution, logarithm of the corrosion rate is a linear function with $1 / T$ (Arrhenius equation):

$\log ($ rate $)=\frac{-E_{\mathrm{a}}^{\circ}}{2.303 R T}+A$

where, $E_{\mathrm{a}}^{\circ}$ is the apparent effective activation energy, $R$ general gas constant and $A$ the Arrhenius pre-exponential factor. A plot of log of corrosion rate obtained by weight loss 
$4 a$

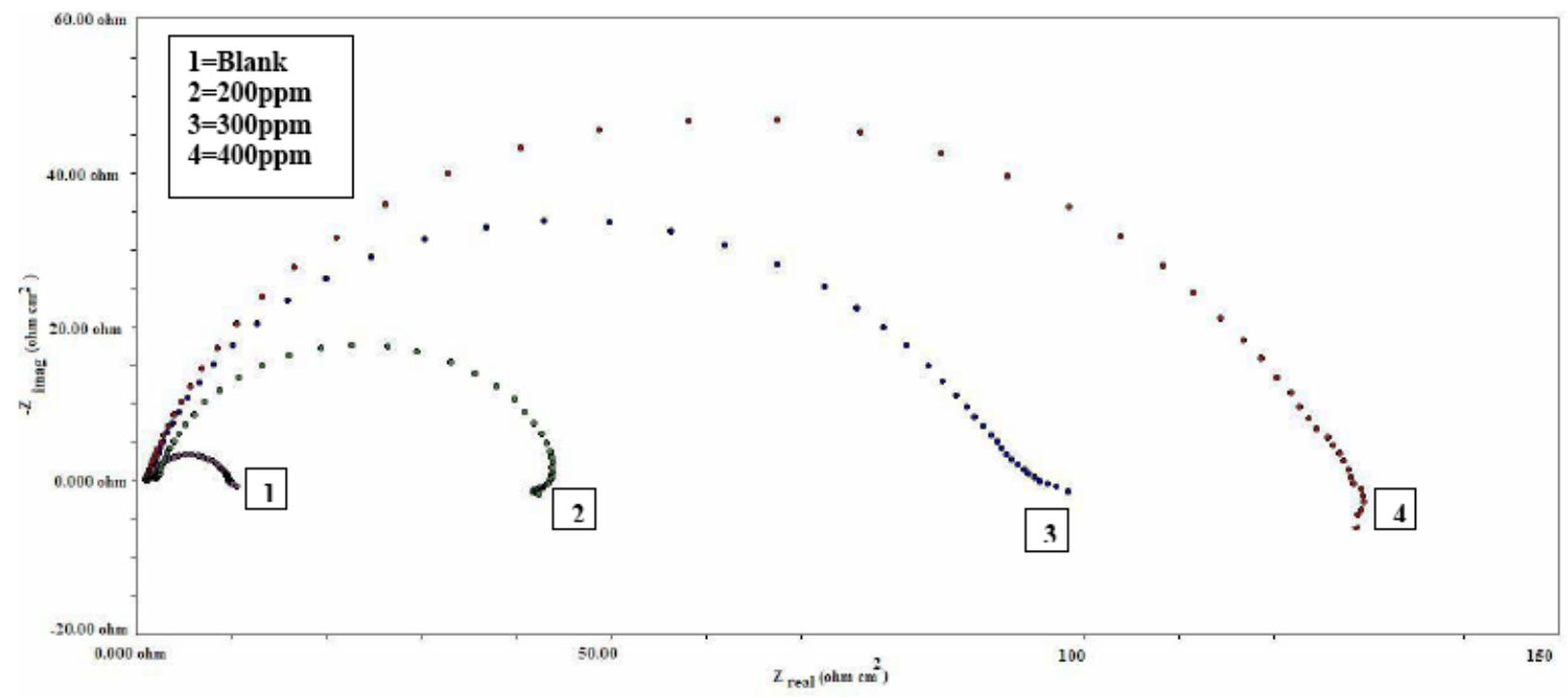

4b

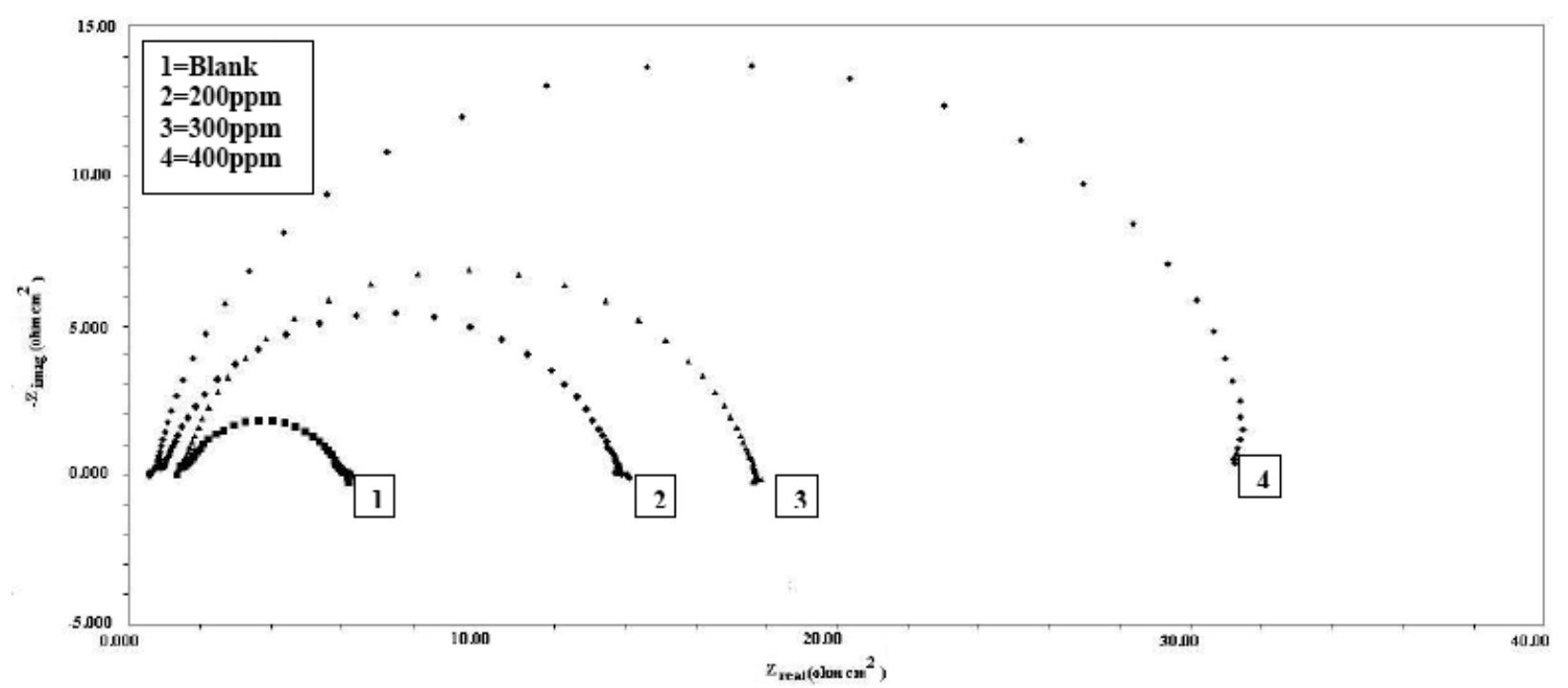

Fig. (4). (a) Nyquist plots in absence and presence of different concentrations of Dapsone in $1 \mathrm{M} \mathrm{HCl}$ and (b) Nyquist plots in absence and presence of different concentrations of Dapsone in $0.5 \mathrm{M} \mathrm{H}_{2} \mathrm{SO}_{4}$.

5a

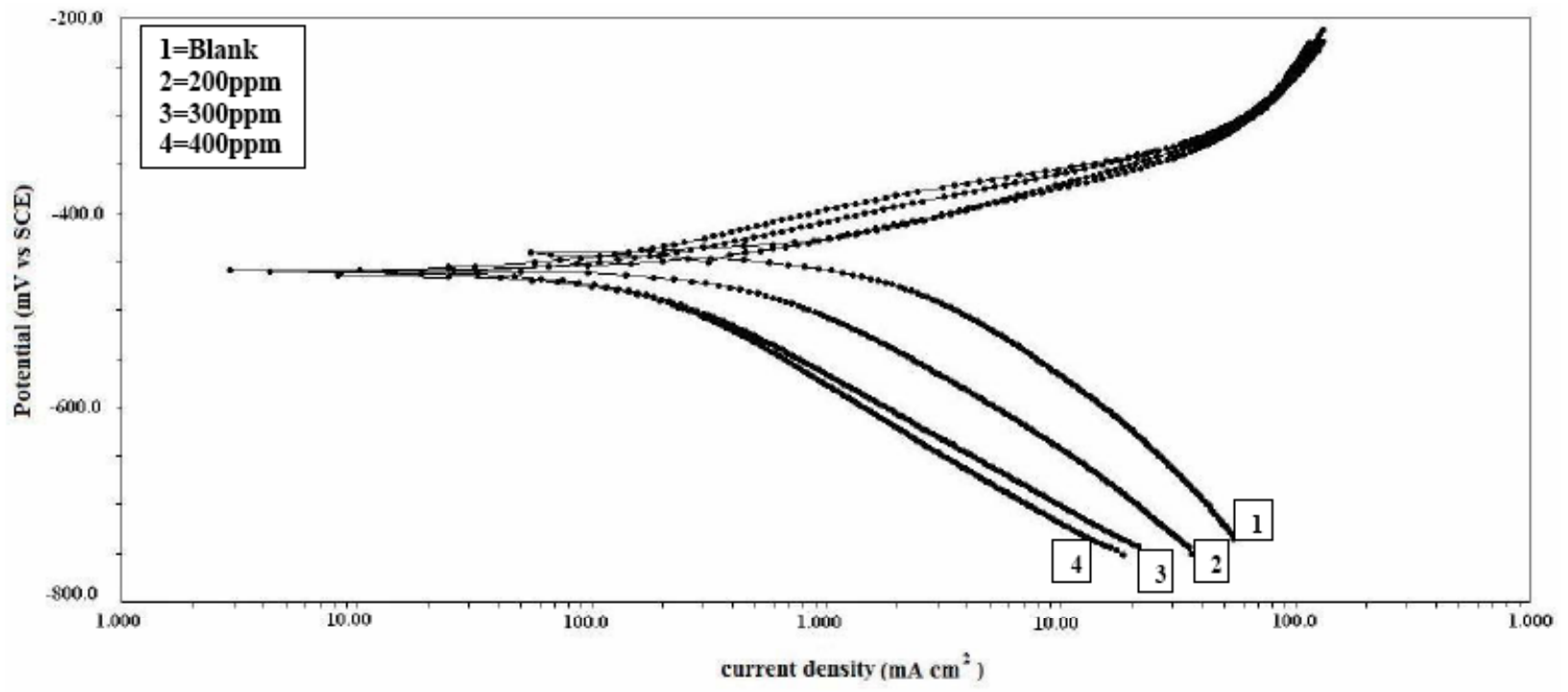


Fig. 5. Contd....

\section{$\mathbf{5 b}$}

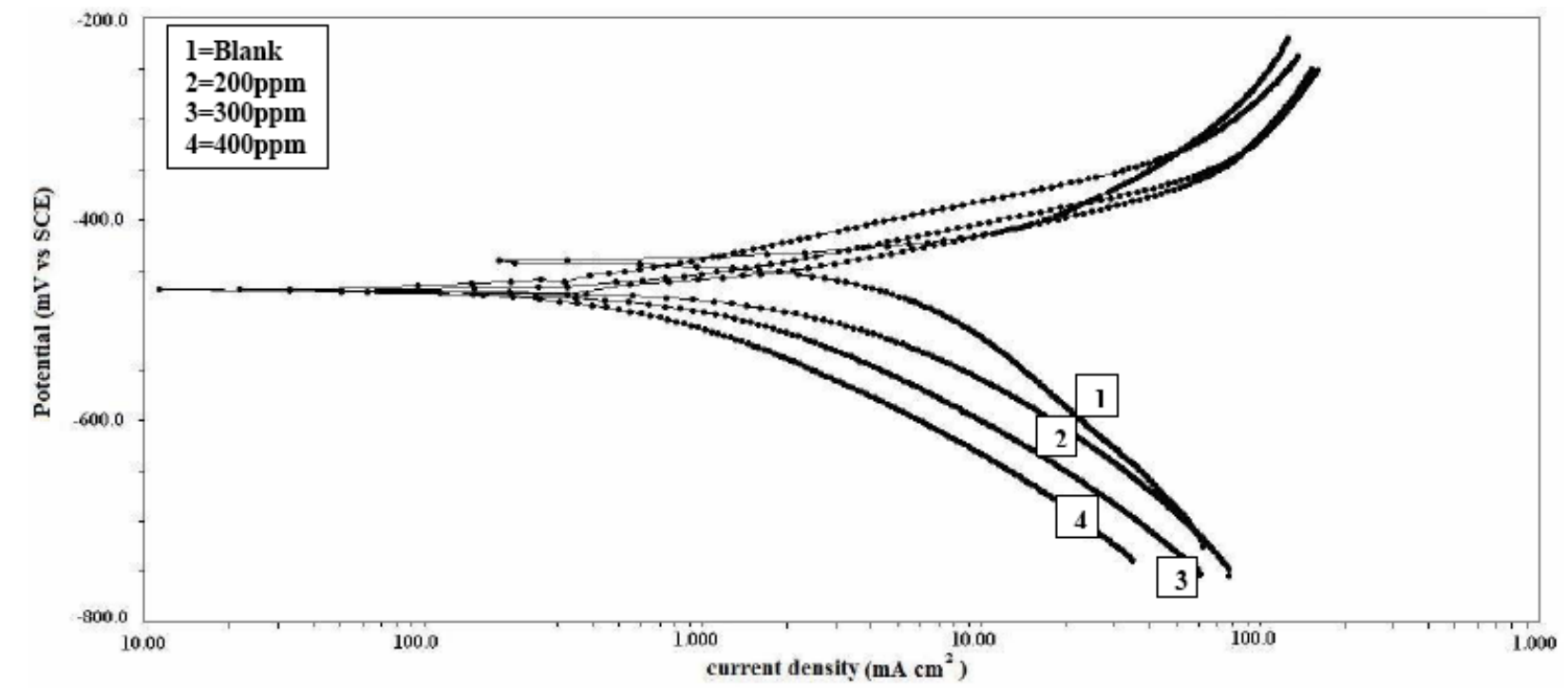

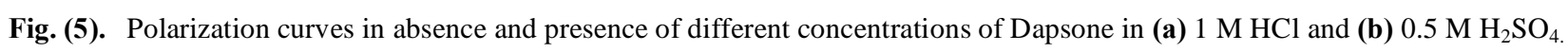

Table 3. Potentiodynamic Polarization Parameters for Mild Steel without and with Different Concentrations of Dapsone in 1 M $\mathrm{HCl}$ and $0.5 \mathrm{M} \mathrm{H}_{2} \mathrm{SO}_{4}$

\begin{tabular}{|c|c|c|c|c|c|c|c|c|}
\hline \multicolumn{6}{|c|}{ Tafel Data } & \multicolumn{3}{|c|}{ Linear Polarization Data } \\
\hline Acid Solution & $\begin{array}{c}\text { Conc. of } \\
\text { Inhibitor }\left(M \times 10^{-4}\right)\end{array}$ & $\begin{array}{c}E_{\text {corr }} \\
(\mathrm{mV} \text { vs SCE) }\end{array}$ & $\begin{array}{c}I_{\text {corr }} \\
\left(\mu \mathrm{A} \mathrm{cm}^{-2}\right)\end{array}$ & $\begin{array}{c}b_{\mathrm{a}} \\
(\mathrm{mV} / \mathrm{dec})\end{array}$ & $\begin{array}{c}b_{\mathrm{c}} \\
(\mathrm{mV} / \mathrm{dec})\end{array}$ & $\mu_{\mathrm{P} \%}$ & $\begin{array}{c}R_{\mathrm{p}} \\
\left(\Omega \mathrm{cm}^{2}\right)\end{array}$ & $\mu_{R_{\mathrm{p}} \%}$ \\
\hline \multirow[t]{4}{*}{$1 \mathrm{M} \mathrm{HCl}$} & 0.0 & -445 & 1530 & 90 & 129 & - & 9.70 & - \\
\hline & 200 & -461 & 345 & 55 & 83 & 74.76 & 43.00 & 77.44 \\
\hline & 300 & -465 & 130 & 54 & 98 & 91.79 & 116.00 & 91.63 \\
\hline & 400 & -462 & 98 & 56 & 76 & 93.81 & 262.2 & 95.38 \\
\hline \multirow[t]{4}{*}{$0.5 \mathrm{M} \mathrm{H}_{2} \mathrm{SO}_{4}$} & 0.0 & -441 & 4799 & 86 & 100 & - & 3.25 & - \\
\hline & 200 & -470 & 1010 & 52 & 69 & 78.95 & 19.00 & 82.89 \\
\hline & 300 & -471 & 960 & 70 & 111 & 79.99 & 20.80 & 84.37 \\
\hline & 400 & -469 & 415 & 65 & 93 & 91.35 & 39.70 & 91.81 \\
\hline
\end{tabular}

measurement versus $1 / T$ gave straight line as shown in Fig. (7a). The values of activation energy $E_{\mathrm{a}}^{\circ}$ obtained from the slope of the lines are given in Table (4). An alternative formula of the Arrhenius equation is the transition state equation [38]:

Rate $=\frac{R T}{N h} \exp \left(\frac{\Delta S^{\circ}}{R}\right) \exp \left(-\frac{\Delta H^{\circ}}{R T}\right)$

where $\mathrm{h}$ is Plank's constant, $\mathrm{N}$ the Avogadro's number, $\Delta S^{\circ}$ the entropy of activation and $\Delta H^{\circ}$ the enthalpy of activation. A plot of $\log \left(C_{\mathrm{R}} / T\right)$ versus $1 / T$ gave a straight line (Fig. 7b), with a slope of $\left(-\Delta H^{\circ} / 2.303 R\right)$ and an intercept of $\left[\log (R / \mathrm{Nh})+\left(\Delta S^{\circ} / 2.303 R\right)\right]$, from which the values of $\Delta S^{\circ}$ and $\Delta H^{\circ}$ were calculated and listed in Table (4). The data shows that thermodynamic activation functions $\left(E_{\mathrm{a}}^{\circ}\right)$ of the corrosion in mild steel in $1 \mathrm{M} \mathrm{HCl}$ and $0.5 \mathrm{M} \mathrm{H}_{2} \mathrm{SO}_{4}$ solution

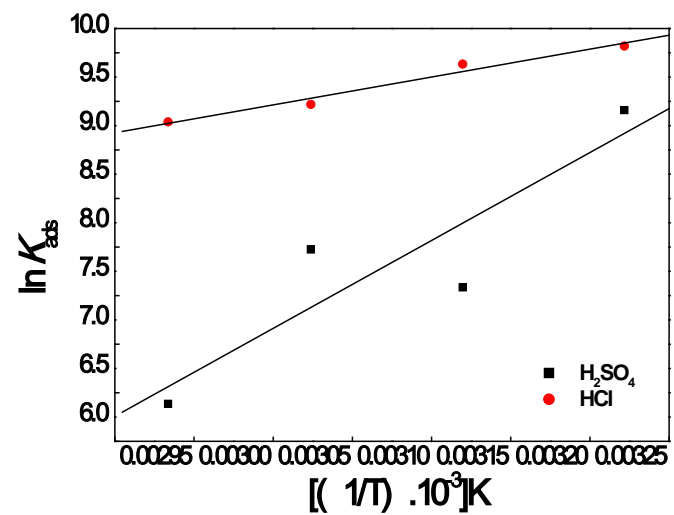

Fig. (6). Plot of $\ln K_{\text {ads }} v s .1 / T$ on the surface of mild steel. 
Table 4. The Values of Activation Parameters $E_{\mathrm{a}}, \Delta H_{\mathrm{a}}^{0}$ and $\Delta S_{\mathrm{a}}^{0}$ for Mild Steel in $1 \mathrm{M} \mathrm{HCl}$ and $0.5 \mathrm{M} \mathrm{H}_{2} \mathrm{SO}_{4}$ in the $\mathrm{Absence} \mathrm{and}^{\circ}$ Presence of Optimum Concentrations of Dapsone

\begin{tabular}{|c|c|c|c|c|c|c|}
\hline Acid Solution & $\begin{array}{c}\text { Inhibitor conc. } \\
\text { (ppm) }\end{array}$ & $\begin{array}{c}E_{\mathrm{a}} \\
\left(\mathrm{kJ} \mathrm{mol}^{-1}\right)\end{array}$ & $\begin{array}{c}-\Delta H_{\mathrm{a}}^{\mathbf{0}} \\
\left(\mathrm{kJ} \mathrm{mol}^{-1}\right)\end{array}$ & $\begin{array}{c}\Delta S_{\mathrm{a}}^{\mathbf{0}} \\
\left(\mathrm{J} \mathrm{mol}^{-1} \mathbf{K}^{-1}\right)\end{array}$ & $\begin{array}{c}\Delta H_{\text {ads }} \\
\left(\mathrm{kJ} \mathrm{mol}^{-1}\right)\end{array}$ & $\begin{array}{c}\Delta G^{\circ}{ }_{a d s} \\
\left(\mathbf{k J} \mathrm{mol}^{-1}\right)\end{array}$ \\
\hline \multirow[t]{2}{*}{$1 \mathrm{M} \mathrm{HCl}$} & 0.0 & 28.77 & 26.11 & 124.48 & - & - \\
\hline & 400.0 & 56.19 & 63.52 & 30.50 & -16.45 & 33.49 \\
\hline \multirow[t]{2}{*}{$0.5 \mathrm{M} \mathrm{H}_{2} \mathrm{SO}_{4}$} & 0.0 & 20.96 & 18.30 & -146.32 & - & - \\
\hline & 400.0 & 47.12 & 44.46 & -85.15 & -16.75 & 32.55 \\
\hline
\end{tabular}

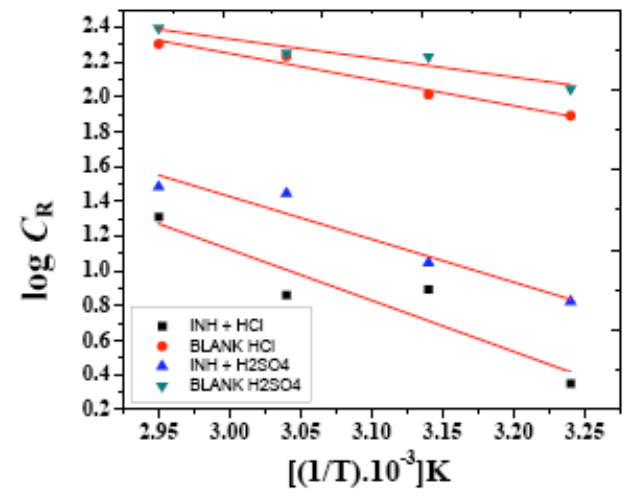

a

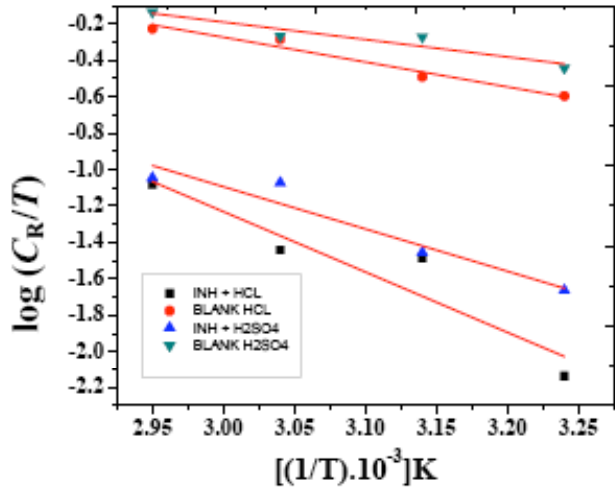

b

Fig. (7). Adsorption isotherm plots for (a) $\log C_{\mathrm{R}}$ vs. $1 / T$ and (b) $\log \left(C_{\mathrm{R}} / T\right)$ vs. $1 / T$.

in the presence of the inhibitor is higher than those in free acid solution indicating that all the inhibitors lowers the inhibition efficiency at higher temperature [39-41]. The negative values of $\Delta S^{\circ}$ and $\Delta H^{\circ}$ indicates that the process of adsorption is exothermic, spontaneous and increases the system order $[42,43]$. Free energy of adsorption $\left(\Delta G_{\text {ads }}^{\mathrm{o}}\right)$ calculated using the following equations [44].

$$
\begin{aligned}
& \Delta G_{\mathrm{ads}}^{\mathrm{o}}=-R T \ln (55.5 K) \\
& K=\frac{\theta}{C(1-\theta)}
\end{aligned}
$$

where, $\theta$ is degree of coverage on the metal surface, $C$ is concentration of inhibitor in mol/l, $R$ is a constant and $T$ is temperature. This value is lesser than $-40 \mathrm{~kJ} / \mathrm{mol}$ indicating that all are physically adsorbed on metal surface as in Table (4) [45]. The negative values of $\Delta G_{\text {ads }}$ indicated the spontaneous adsorption of inhibitor on surface of mild steel [46].

It is well known that organic inhibitors establish inhibition by adsorption onto the metal surface. The adsorption of inhibitors influenced by the chemical structures of organic compounds, nature and surface charge of metal, the distribution of charge in molecule and type of aggressive media [47, 48]. The physical adsorption requires the presence of electrically charged metal surface and charged species in the bulk of solution. In the case of chemisorption process involves charge sharing or charge transfer from the inhibitor molecule to the metal surface. This is possible in case of positive as well as negative charges on this surface. The presence, with a transition metal, having vacant and low-energy electron orbital of an inhibitor molecule having relatively loosely bound electrons or heteroatoms with lone-pair electrons facilitates this adsorption [49].

The mechanism of corrosion inhibition may be explained on basis of adsorption behavior [50]. Basic information on the interaction between the inhibitor and the mild steel surface can be provided by the adsorption isotherm. For this purpose, the values of surface coverage $(\theta)$ at different concentrations of dapsone in acid media in the temperature range (308-338 $\mathrm{K}$ ) have been used to explain the best isotherm to determine the adsorption process. The adsorption of an organic adsorbate on to metal-solution interface was donated by a substitutional adsorption process between the organic molecules in the aqueous solution $\mathrm{Org}_{(\mathrm{sol})}$ and the water molecules on the metallic surface $\mathrm{H}_{2} \mathrm{O}_{(\text {ads })}$ [51].

$$
\operatorname{Org}_{(\text {(sol) }}+x \mathrm{H}_{2} \mathrm{O} \rightarrow \mathrm{Org}_{\text {(ads) }}+x \mathrm{H}_{2} \mathrm{O}_{\text {(sol) }}
$$

Where, $\operatorname{Org}_{(\text {(sol) }}$ and $\operatorname{Org}_{(\text {ads })}$ are the organic molecules in the aqueous solutions and adsorbed on the metallic surface, respectively, $\mathrm{H}_{2} \mathrm{O}_{(\text {ads })}$ is the water molecules on the metallic surface, $x$ is the size ratio representing the number of water molecules replaced by one molecule of organic adsorbate.

Attempts were made to fit these $\theta$ values to various isotherm including Frumkin, Langmuir, Temkin. According to these isotherms, $\theta$ is related to the inhibitor concentration $\left(C_{\mathrm{inh}}\right)$ : 


$$
\begin{array}{ll}
\theta=\frac{b C_{\text {inh }}}{1+b C_{\text {inh }}} & \text { (Langmuir isotherm) } \\
\exp (-2 a \theta)=K C_{\text {inh }} & \text { (Temkin isotherm) }
\end{array}
$$

Where, $b$ designates the adsorption coefficient in equation (15), $a$ the molecular interaction parameter, $\mathrm{K}$ is the equilibrium constant of the adsorption process in equation (16). The best fit was obtained with Langmuir isotherm. The first stage in the action mechanism of inhibitor in acid media is adsorption on the metal surface [52]. In most inhibition studies, the formation of donor-acceptor surface complexes between $\pi$ electrons of inhibitor and the vacant d-orbital of metal were postulated [53].

\section{MECHANISM OF INHIBITION}

Corrosion inhibition of mild steel in $1 \mathrm{M} \mathrm{HCl}$ and $0.5 \mathrm{M}$ $\mathrm{H}_{2} \mathrm{SO}_{4}$ by Dapsone can be explained on the basis of molecular adsorption. The compound inhibits corrosion by controlling both the anodic and cathodic reactions. From the data presented in Table (3) it is clear that dapsone inhibits corrosion of mild steel simply by blocking both cathodic and anodic site. Corrosion inhibition of Dapsone is attributed to the presence of $\pi$ electrons, quaternary nitrogen atom and the larger molecular size.

\section{CONCLUSIONS}

1. Dapsone functioned as a good inhibitor for the corrosion of mild steel in $1 \mathrm{M} \mathrm{HCl}$ and $0.5 \mathrm{M} \mathrm{H}_{2} \mathrm{SO}_{4}$ and the inhibiting efficiency value increased with the inhibitor concentration.

2. The electrochemical impedance study showed that corrosion inhibition of mild steel in molar hydrochloric acid solution takes place by adsorption process. Tafel polarization curves indicated that the dapsone acted as mixed type in both $\mathrm{HCl}$ and $\mathrm{H}_{2} \mathrm{SO}_{4}$ solution.

3 . The increasing value of CPE exponent $(n)$ with increasing inhibitor concentration indicated that surface roughness decreased with increasing inhibitor concentration.

4. The adsorption of the dapsone on the mild steel surface in acid solution obeyed Langmuir adsorption isotherm.

\section{REFERENCES}

[1] Ali, S.A.; Saeed, M.T.; Rahman, S.V. The isoxazolidines: a new class of corrosion inhibitors of mild steel in acidic medium. Corrosion Sci., 2003, 45(2), 253-266.

[2] Lagrenee, M.; Mernari, B.; Bouanis, M.; Traisnel, M.; Bentiss, F. Study of the mechanism and inhibiting efficiency of 3,5-bis(4methylthiophenyl)-4H-1,2,4-triazole on mild steel corrosion in acidic media. Corrosion Sci., 2002, 44(3), 573-588.

[3] Quraishi, M. A.; Sardar, R. Aromatic triazoles as corrosion inhibitors for mild steel in acidic environments. Corrosion, 2002, 58(9), 748-755.

[4] Singh, A. K.; Quraishi, M.A. The effect of some bis-thiadiazole derivatives on the corrosion of mild steel in hydrochloric acid. Corrosion Sci., 2010, 52(4), 1373-1385.

[5] Quraishi, M. A.; Ansari, F. A. Corrosion inhibition by fatty acid triazoles for mild steel in formic acid. J. Appl. Electrochem., 2003, 33(3), 233-238.

[6] Singh, A. K.; Quraishi, M. A. Inhibiting effects of 5-substituted isatin-based Mannich bases on the corrosion of mild steel in hydrochloric acid solution. J. Appl. Electrochem., 2010, 40(7), 1293-1306.
Quraishi, M.A.; Ahamad, I.; Singh, A. K.; Shukla, S. K.; Lal, B.; Singh, V. [N(Piperidinomethyl)3[(pyridylidene)amino] isatin: A new and effective acid corrosion inhibitor for mild steel. Mater. Chem. Phys., 2008, 112(3), 1035-1039.

[8] Bentiss, F.; Lagrenee, M.; Traisnel, M.; Hornez, J. C. The corrosion inhibition of mild steel in acidic media by a new triazole derivative. Corrosion Sci., 1999, 41(4), 789-803.

[9] Growcock, F.B.; Frenier, W.W.; Andreozzi, P.A. Inhibition of steel corrosion in hel by derivatives of cinnamaldehyde .1. corrosion inhibition model. Corrosion, 1989, 45(12), 1007-1012.

[10] Lukovits, I.; Kalman, E.; Palinkas, G. Nonlinear group-contribution models of corrosion inhibition. Corrosion, 1995, 51(3), 201-205.

[11] Ayers, R.C.; Jr. Hackerman, N. Corrosion inhibition in $\mathrm{HCl}$ using methyl pyridines. J. Electrochem. Soc., 1963, 110(6), 507-513.

[12] Ahamad, I.; Quraishi, M.A. Mebendazole: New and efficient corrosion inhibitor for mild steel in acid médium. Corrosion Sci., 2010 52(2), 651-656.

[13] Quraishi, M. A.; Shukla, Sudhish Kumar. Poly(anilineformaldehyde): a new and effective corrosion inhibitor for mild steel in hydrochloric acid. Mater. Chem. Phys., 2009, 113(2), 685689.

[14] Moretti, G.; Guidi, F.; Grion, G. Tryptamine as a green iron corrosion inhibitor in $0.5 \mathrm{M}$ deaerated sulphuric acid. Corrosion Sci., 2004, 46(2), 387- 403.

[15] Giacomelli, F. C.; Giacomelli, C.; Amadori, M. F.; Schmidt, V.; Spinelli, A. Inhibitor effect of succinic acid on the corrosion resistance of mild steel: Electrochemical, gravimetric and optical microscopic studies. Mater. Chem. Phys., 2004, 83(1), 124-128.

[16] Ferreira, E. S.; Giacomelli, C.; Giacomelli, F. C.; Spinelli, A. Evaluation of the inhibitor effect of L-ascorbic acid on the corrosion of mild steel. Mater. Chem. Phys., 2004, 83(1), 129-134.

[17] El Sherbini, E. E. F. Effect of some ethoxylated fatty acids on the corrosion behaviour of mild steel in sulphuric acid solution. Mater. Chem. Phys., 1999, 60(3), 286-290.

[18] Morad, M. S. Inhibition of iron corrosion in acid solutions by Cefatrexyl: Behaviour near and at the corrosion potential. Corrosion Sci., 2008, 50(2), 436- 448.

[19] Quraishi, M. A.; Rawat, J.; Ajamal, M. Dithiobiurets: a novel class of acid corrosion inhibitors for mild steel. J. Appl. Electrochem., 2000, 30(6), 745- 751 .

[20] Abdallah, M. Antibacterial drugs as corrosion inhibitors for corrosion of aluminium in $\mathrm{HCl}$ solution. Corrosion Sci., 2004, 46(8), $1981-1996$.

[21] Singh, A. K.; Quraishi, M.A. Inhibitive effect of diethylcarbamazine on the corrosion of mild steel in hydrochloric acid. Corrosion Sci., 2010, 52(4), 1529-1535.

[22] Pandey, P. C.; Prakash R. Characterization of electropolymerized polyindole; application in the construction of a solid-state ion-selective electrode. J. Electrochem. Soc., 1998, 145(12), 41034107.

[23] Mohan, J.; Joshi, S.; Prakash, R.; Srivastava, R. C. Novel Ni(II) mixed ligand complex modified electrode: catalytic effect on anodic oxidation of phenol. Electroanalysis, 2004, 16(7), 572-576.

[24] Schorr, M.; Yahalom, J. The significance of the energy of activation for the dissolution reaction of metal in acids. Corrosion Sci. 1972, 12(11), 867-868

[25] Martinez, S.; Stern, I. Inhibitory mechanism of low-carbon steel corrosion by mimosa tannin in sulphuric acid solutions. J. Appl. Electrochem., 2001, 31(9), 973-978.

[26] Oguzie, E.E. Influence of halide ions on the inhibitive effect of congo red dye on the corrosion of mild steel in sulphuric acid solution. Mater. Chem. Phys., 2004, 87(1), 212- 217.

[27] Popova, A.; Sokolova, E.; Rsicheva, S.; Christov, M. AC and DC study of the temperature effect on mild steel corrosion in acid media in the presence of benzimidazole derivatives. Corrosion Sci. 2003, 45(1), 33-58.

[28] Umoren, S.A.; Ogbobe, O.; Ebenso, E.E.; Ekpe, U.J. Effect of halide ions on the corrosion inhibition of mild steel in acidic medium using polyvinyl alcohol. Pigment Resin. Technol., 2006, 35(5), 284-292.

[29] Etre, A. Y. Inhibition of aluminum corrosion using Opuntia extract. Corrosion Sci., 2003, 45(11), 2485-2495.

[30] Singh, A. K.; Quraishi, M.A. Effect of Cefazolin on the corrosion of mild steel in $\mathrm{HCl}$ solution. Corrosion Sci., 2010, 52(1), 152-160. 
[31] Brinic S.; Grubac Z.; Babic R.; Metikos-Hukovic M. Proceedings of $8^{\text {th }}$ European Symposium on Corrosion Inhibitors, 1995, Ferrara Italy, 1, 197

[32] Gomma, M. K.; Wahdan, M. H. Inhibition action of n-decylamine on the dissolution of low carbon steel in sulphuric acid. Indian $J$. Chem. Technol., 1955, 2(2), 107-110.

[33] Da Costa, S.L.F.A. Electrochemical behavior of copper in $0.5 \mathrm{M}$ $\mathrm{H}_{2} \mathrm{SO}_{4}$ solutions in the absence and presence of $\mathrm{Fe}(\mathrm{III})$ and benzotriazole. Corrosion, 1989, 45(6), 472- 477.

[34] Jha, J.L. Studies of the adsorption of amide derivative during acid corrosion of pure iron and its characterization. Ph.D. thesis, Delhi University, Delhi, 1990.

[35] Quraishi, M.A.; Khan, S. Thiadiazoles-A potential class of heterocyclic inhibitors for prevention of mild steel corrosion in hydrochloric acid solution. Indian J. Chem. Technol., 2005, 12, 576-581.

[36] Breslin, C.B.; Carrol, W.M. The activation of aluminium by indium ions in chloride, bromide and iodide solutions. Corrosion Sci., 1993, 34(2), 327-341.

[37] Khedr, M.G.A.; Lashien, M.S. The role of metal cations in the corrosion and corrosion inhibition of aluminium in aqueous solutions. Corrosion Sci., 1992, 33(1), 137-151.

[38] Singh, A. K.; Quraishi, M.A. Effect of 2,2' benzothiazolyl disulfide on the corrosion of mild steel in acid media. Corrosion Sci., 2009, 51(11), 2752-2760.

[39] Hosseini, M. G.; Ehteshamzadeh, M.; Shahrabi, T. Protection of mild steel corrosion with Schiff bases in $0.5 \mathrm{M} \mathrm{H} 2 \mathrm{SO} 4$ solution. Electrochem. Acta, 2007, 52(11), 3680-3685.

[40] Bentiss, F.; Traisnel, M.; Lagrenee, M. The inhibition action of 3, 6-bis(2-methoxyphenyl)-1, 2-dihydro-1, 2, 4, 5-tetrazine on the corrosion of mild steel in acidic media. Corrosion Sci., 2000, 42(1), 127-146.

[41] Murlidharan, S.; Phani, K. L. N.; Pitchumani, S.; Ravichandran, S. Polyamino-benzoquinone polymers: a new class of corrosion inhibitors for mild steel. J. Electrochem. Soc., 1995, 142(5), 14781483

[42] Morales-Gil, P.; Negron-Silva, G.; Romero-Roma, M.; AngelsChaves, C.; Palomar-Prdave, P. Corrosion inhibition of pipeline steel grade API 5L X52 immersed in a $1 \mathrm{M} \mathrm{H}_{2} \mathrm{SO}_{4}$ aqueous solution using heterocyclic organic molecules. Electrochem. Acta, 2004, 49(26), 4733-4741.

[43] Abdallah, M. Rhodanine azosulpha drugs as corrosion inhibitors for corrosion of 304 stainless steel in hydrochloric acid solution. Corrosion Sci., 2002, 44(4), 717-728.

[44] Hirozawa S. T. Proceedings of $8^{\text {th }}$ European Symposium on Corrosion Inhibitors. Ann. University, 1995, Ferrara, Italy, 1, 25.

[45] Hosseini, M.; Mertens, S.F.L.; Ghorbani, M.; Arshadi, M.R. Asymmetrical Schiff bases as inhibitors of mild steel corrosion in sulphuric acid media. Mater. Chem. Phys., 2003, 78(3), 800-808.

[46] Shukla, J.; Pitre, K.S. Electrochemical behaviour of brass in acid solutions and the inhibitive effect imidazole. Corrosion Rev., 2002, 20(3), 217-230.

[47] Bentiss, F.; Mehdi, B.; Mernari, B.; Traisnel, M.; Vezin, H. Electrochemical and quantum chemical studies of 3,5-di(n-tolyl)-4amino-1,2,4-triazole adsorption on mild steel in acidic media. Corrosion, 2002, 58(5), 399-407.

[48] Tebbji, K.; Hammouti, B.; Oudda, H.; Ramdani, A.; Benkadour, M. The inhibitive effect of bipyrazolic derivatives on the corrosion of steel in hydrochloric acid solution. Appl. Surf. Sci., 2005, 252(5), 1378-1385.

[49] Yurt, A.; Balaban, A.; Ustun, Kandemir S.; Bereket, G.; Erk, B. Investigation on some Schiff bases as $\mathrm{HCl}$ corrosion inhibitors for carbon steel. Mater. Chem. Phy., 2004, 85(2), 420-426.

[50] Gomma, G.K.; Wahdan, M.H. Effect of temperature on the acidic dissolution of copper in the presence of amino acids. Mater. Chem. Phys., 1994, 39(2), 142-148.

[51] Quraishi, M.A.; Sardar, R. Corrosion inhibition by fatty acid triazoles for mild steel in formic acid. J. Appl. Electrochem., 2003 , 33(4), 1163-1168.

[52] Muralidharan, S.; Quraishi, M.A.; Iyer, S.K.V. The effect of molecular structure on hydrogen permeation and the corrosion inhibition of mild steel in acidic solutions. Corrosion Sci., 1995, 37(11), $1739-1750$

[53] Trabenelli G., Mansfeld F. Corrosion Mechanisms. Marcel Dekker, New York, 1987, vol. 109 